\title{
Studies of sea surface temperatures in selected northern Norwegian fjords using Landsat TM data
}

\author{
M. HAAKSTAD, J. W. KÖGELER and S. DAHLE.
}

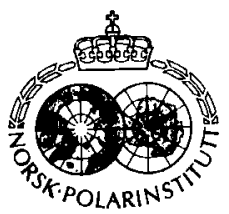

Haakstad, M., Kögeler, J. W. \& Dahle, S. 1994: Studies of sea surface temperatures in selected northern Norwegian fjords using Landsat TM data. Polar Research 13, 95-103

\begin{abstract}
Remote sensing is evaluated as a tool for studying oceanographic phenomena. Data from the infrared channel of Thematic Mapper onboard Landsat 5 were used to map the spatial distribution of sea surface temperatures in selected fjords in northern Norway. Sea surface temperature charts provided clear indications of surface current patterns, upwellings, convergences, etc. The complex pattern of currents found in fjords is, to varying degrees, affected by tides and fresh water run-off, as well as by hydrographic, meteorological and topographical conditions. In northern Norway the surface circulation is strongly influenced by inland cold air flows during prolonged periods of cold weather.

This study demonstrates that remotely sensed data can be used as an important supplement to traditional hydrographical and meteorological observations in order to understand the distribution of temperatures and circulation patterns in the surface layers of fjords and coastal waters.
\end{abstract}

M. Haakstad, School of Fisheries and Aquaculture Nordland College, N-8002 Bodø, Norway; J. W. Kögeler and S. Dahle, Akvaplan-niva A/S, P. O. Box 735, N-9001 Tromsø, Norway.

\section{Introduction}

The coast of Norway is indented by numerous fjord inlets. Not all of these fit the classical definition of a fjord given by Pritchard (1952): an elongated indenture of the coastline containing a relatively deep basin with a shallow sill at the mouth. This geomorphological definition excludes some of the northernmost fjords, which have no sills. Later classifications take into account other parameters such as circulation and hydrography. However, the important matter in this context is that a fjord is a glacially cut coastal structure which penetrates from the coast into the mountainous Norwegian landscape. In addition to geomorphology, freshwater runoff, climate, tide and exchange processes with the coastal ocean influence the circulation and hydrography of fjords. Since all these parameters vary along the Norwegian coast, fjord circulation and hydrography tend to be very different even in neighbouring fjords.

In the northernmost part of Norway the stratification is completely broken up during winter, with vertical convection from top to bottom and a homogeneous temperature in the coldest months of the year; February, March and April (Sælen 1950; Eilertsen et al. 1981; Nordgaard et al. 1982).
The fjords in the area covered by this survey remain weakly stratified even in the coldest months of the year (Molvær et al. 1984; Haakstad 1984). However, because salinity is more important than temperature in determining the density of cold water, there may be temperature gradients even if the stability is very weak. In late winter the surface layer is usually cold, while the intermediate and deep waters are considerably warmer and more saline. Upwelling and vertical mixing, therefore, are easy to detect as aberrations in surface temperature.

Remote sensing can be an appropriate method for studying the winter surface temperature and circulation in fjords and coastal regions (Kögeler \& Dahle 1991). In this paper satellite observed sea surface temperature (SST) is compared with the sea surface temperature distribution expected from the observed wind at the meteorological stations in the study area.

\section{Material and methods}

\section{Satellite imagery and processing}

The area surveyed for this study has a complex and differentiated topography. A thermal infraredsensor with high spatial resolution is required 
to obtain reliable satellite data over areas with narrow fjords, sounds, inlets, small islands and extensive skerries. For this reason the Landsat Thematic Mapper (TM) instrument was chosen for use.

The Landsat-TM instrument has 6 bands with 16 sensors per band, each with a ground field view (GFV) of $30 \mathrm{~m}$. The thermal band (band 6), however, has only four sensors, each with a GFV of $120 \mathrm{~m}$. In order to make band 6 images overlap with images from other spectral bands, each thermal pixel is usually duplicated three times in both sample and line direction. This means that pure pixels, i.e. pixels with information that is not contaminated by temperatures over land areas, can only be found in waters wider than $120 \mathrm{~m}$. Consequently, reliable thermal data can only be found over waters wider than 240 metres.

Weather observation reports obtained from the Norwegian Meteorological Institute (DNMI), and "quick-looks" (photographic presentations of satellite raw data acquired in the visible range of the solar spectrum) from another sensor onboard Landsat-5 (Multi Spectral Scanner, MSS) were used to eliminate scenes with such disturbing elements as clouds and fog. Two TM scenes were selected for this study. The scenes covering an area of $185 \mathrm{~km} \times 370 \mathrm{~km}\left(641 / 2^{\circ}\right.$ to $\left.68^{\circ} \mathrm{N}\right)$ were acquired on 6 March 1987. However, this paper only deals with a minor part of the entire area. The data discussed in this paper are from the area indicated with a rectangle in Fig. 1.

The Landsat-5 TM computer compatible tapes were ordered from the ESA (European Space Agency) Earthnet Station in Sweden and processed at Troms $\emptyset$ Satellite Station in Norway. Data processing was performed on a $I^{2} S$ interactive image processor (International Imaging Systems, system 600 ) running on a uVAX II host computer. Information from land and sea areas was separated using band 4 (near infra-red) data.

The periodic striping across the thermal data set was partly removed through histogram modification, which is a simple gain and bias model which does not significantly modify the resultant pixel values. As there is no reliable calibration algorithm developed for Landsat (TM) thermal data, a colour-coded sea surface temperature scale was designed using a regression equation between pixel values and in situ temperatures. After a thermal image had been colour-coded, it was merged with a band 4 black and white image of land and ice areas, thus making it possible to

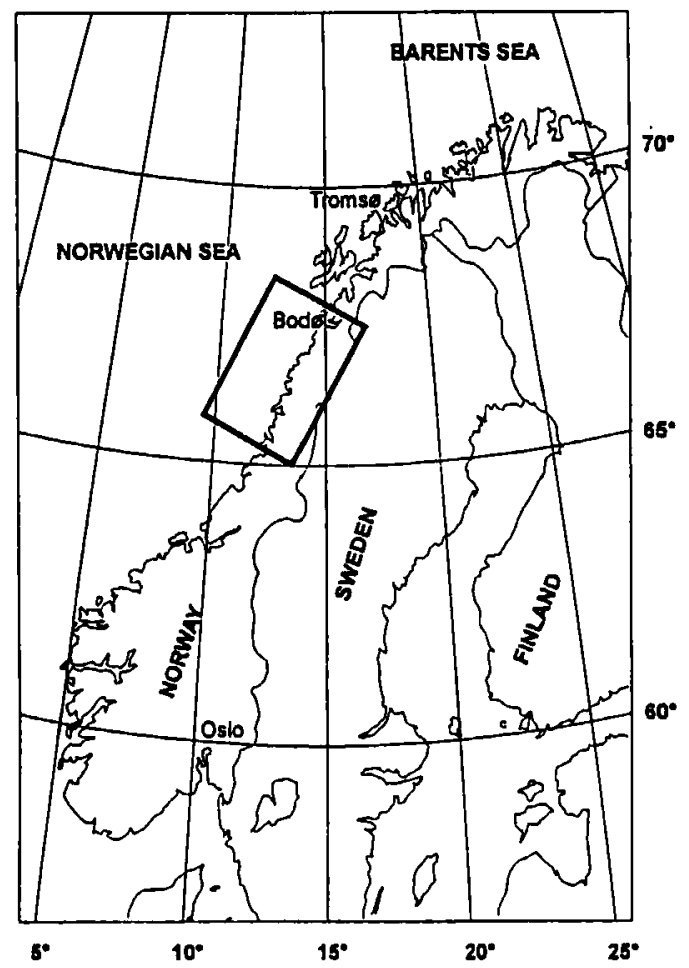

Fig. 1. Geographical coverage of the data set applied in this report. The rectangle defines the remote sensed area discussed in this report.

delineate ice-covered waters and geomorphological features. Finally the images were geometrically corrected.

In situ sea surface temperatures were measured in the upper $3 \mathrm{~m}$ and within 6 hours of the Landsat over-pass. Data were obtained from 21 fish farms, an automatic measurement buoy, and from a ship equipped with thermograph.

The temperature measurements were evaluated with respect to accuracy, reliability and local conditions. Unreliable data and data collected from areas that were clearly affected by clouds or freshwater run-off were excluded, leaving 27 in situ measurements for calibration purposes.

No hydrographic depth profiles taken simultanous with the satellite observations were available. However, the general hydrography of these fjords is relatively well known from earlier observations (Molvær et al. 1984; Haakstad 1984).

\section{Meteorological data}

For at least one month preceding satellite overpass, meteorological charts and detailed obser- 
vation series for wind strength and direction, air and sea surface temperatures, and humidity and precipitation were available. Climatological data were also obtained from all the meteorological observation stations in the study area (DNMI, unpubl. reports).

Wind data are based on wind observations from the meteorological stations established by the Norwegian Meteorological Institute. Some of these stations take 3 observations per day, while others take 4 equispaced observations per day. Seven meteorological stations measured wind in the study area during the winter of 1987; one offshore station, three in the Ranfjord area, and three in the Skjerstadfjord/Saltenfjord area. These meteorological stations covered the entire area from the innermost fjord to the coastal area beyond the fjord.

\section{Wind stress on the sea surface}

In winter, wind is the dominant force effecting fjord circulation. Therefore it is important to obtain a good estimate for the energy transfer from the atmosphere to the ocean. In order to do so, it is important to have a realistic value for the drag coefficient $\left(c_{d}\right)$. In this paper the drag coefficient given by Smith (1980) is used:

$$
\begin{array}{rrr}
c_{d}=1 / 1000 & w \leq 6 \mathrm{~m} / \mathrm{s} \\
c_{d}=\frac{(0.61+0.063|w|)}{1000} & 6 \mathrm{~m} / \mathrm{s}<w \leq 22 \mathrm{~m} / \mathrm{s} \\
c_{d}=2 / 1000 & w>22 \mathrm{~m} / \mathrm{s}
\end{array}
$$

where $w$ is the wind speed $(\mathrm{m} / \mathrm{s})$ in 10 metres.

The duration of a certain wind field is of great importance. In order to visualize the duration and stability of the windfield, the accumulated daily mean wind stress $\mathrm{W}_{\mathrm{s}}$ (in direction $\alpha$ ) is calculated as follows:

$$
\mathrm{w}_{\mathrm{s}}=\Sigma_{\mathrm{T}}
$$

with:

$$
\begin{aligned}
& \mathrm{T}=\frac{1}{\mathrm{n}} \sum_{i=1}^{n} \tau_{i} \\
& \tau_{i}=|\tau| \cos (\beta-\alpha) \\
& \tau=\mathrm{c}_{\mathrm{d}} \rho_{\alpha}|\mathrm{w}| \mathrm{w}
\end{aligned}
$$

where $\mathrm{n}$ is the number of observations per day, $\beta$ is the downwind direction, and $\rho_{\mathrm{a}}$ is the air density.

\section{Results}

In the central part of the Ranfjord, water-land separation was not completely accurate. However, in the rest of the area land and water are separated correctly.

In situ temperatures ranged from 0.9 to $4^{\circ} \mathrm{C}$. Pixel values in the raw data varied from 78 to 85 (on a scale of 0 to 255). The correlation coefficient for the correspondence between satellite pixel values and in situ sea surface temperatures was 0.95 . The sea surface temperature image made from the satellite data is shown in Fig. 2.

Based on the satellite imagery the study area may be divided into three regions: an offshore area with high sea surface temperature, a coastal zone with low sea surface temperature, and the fjords where there is considerable variation in sea surface temperature. The inner parts of some of the shorter fjords have common sea surface temperatures nearly as high as the offshore water masses, while others have a sea surface temperature close to freezing.

The fjords discussed in this paper are all deepsill fjords, with the exception of Skjerstadfjord, which has a shallow sill. The deepwater beneath sill depth may be stagnant for long periods of time and will never come to the surface of the fjord. None of the fjords discussed in this paper have a distinct layered structure and the stability of the entire water mass is very weak in winter.

A typical depth profile for the hydrography of one of these fjords in late winter is shown in Fig. 3. The temperature and salinity increase slightly with depth. This depth-dependent temperature variation makes it possible to identify the atypical watermasses on SST maps where wind brings subsurface watermasses to the surface.

\section{The meteorological situation before and during the satellite observations}

Air movements are complicated in fjords and coastal areas making it difficult to find wind observation sites representative of large areas. However, in winter, prolonged periods with high pressure over Scandinavia can occur. During such periods the wind pattern is stable. In open areas the direction of the surface wind with respect to the surface isobars is on the order of less than $20^{\circ}$ to the left of the isobars (Børresen 1987). Inland the wind is down-fjord. But, on the coast the wind direction is more variable. The SST map for 6 March (Fig. 2) is from the end of such a period. 


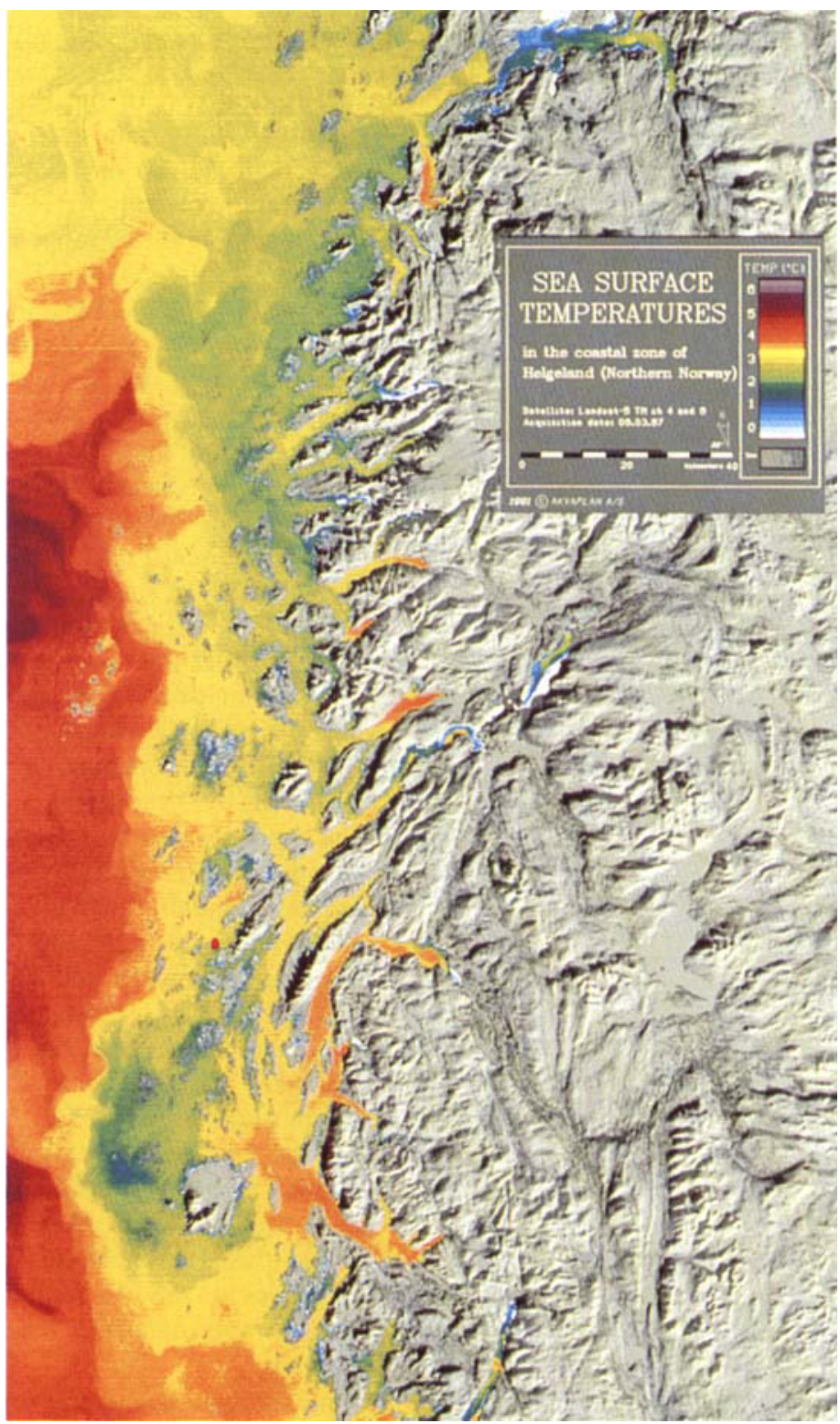

Fig. 2. Remotely sensed sea surface temperature, 6 March, 1987.

The surface pressure chart for 12 UTC on 2 March, 1987 is representative of the pressure over northern Scandinavia during the period from the end of February to 6 March, 1987 (Deutscher Wetterdienst 1987), Fig. 4. The daily mean wind at the meteorological stations in the study area on 2 March is shown in Fig. 5.

During winter periods with high pressure over
Scandinavia, a surface layer of cold air forms and drains to the coastal area through the valleys and fjords. Such mountain-lee gravity wave winds were studied by Macklin et al. (1988). They concluded that a geotriptic (geotriptic is the balance between pressure gradient, Coriolis force, and frictional forces, Johnson (1966)) adjustment of the regional surface wind field is nearly achieved 


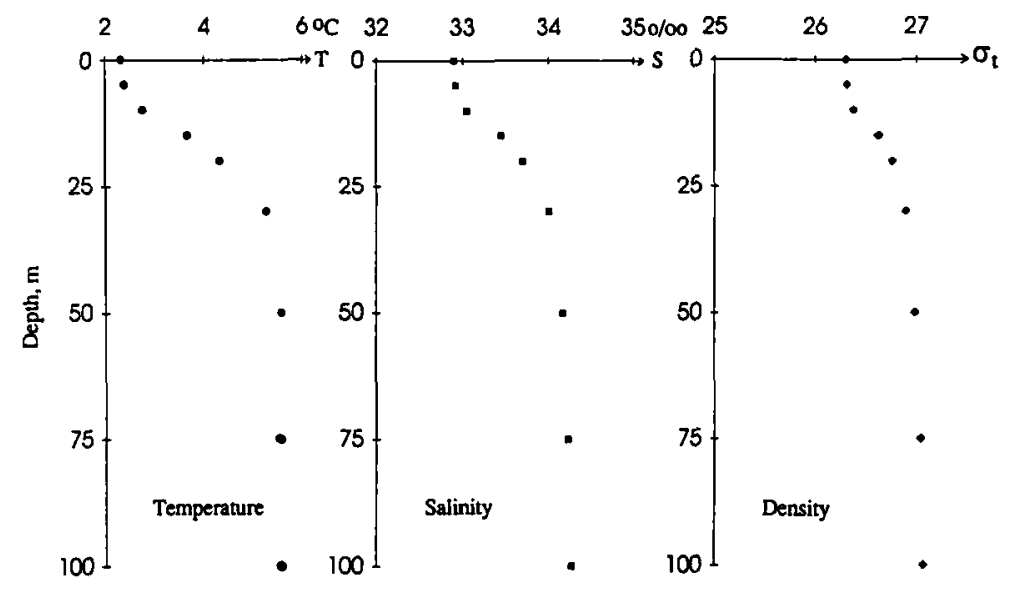

Fig. 3. Typical vertical profiles for temperature, salinity and density (Glomfjord, $N 66^{\circ} 49,5^{\prime} \mathrm{E} 13^{\circ} 39^{\prime}$, on 17 March 1981 ).

within a distance from the mountain barrier corresponding to the Rossby radius of deformation (R):

$$
\mathrm{R}=\frac{\sqrt{\mathrm{g} \frac{\theta-\theta_{0}}{\theta_{\mathrm{o}}} \mathrm{H}}}{\mathrm{f}}
$$

where $H$ is the boundary layer thickness, $\theta-\theta_{0}$ is the inversion strength, $\theta_{0}$ is the average potential temperature in the boundary layer, $f$ is the Cori-

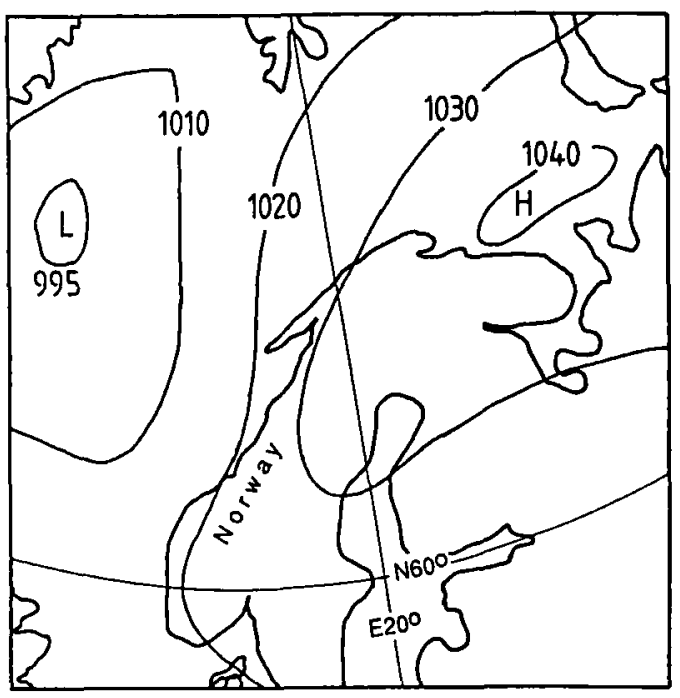

Fig. 4. Surface pressure (hPa) 12 UTC, 2 March 1987. olis parameter, and $\mathrm{g}$ is the acceleration due to gravity.

The temperature inversion is easily identified on the plot of the vertical atmospheric temperature profile for Bod $\emptyset$ on 2 March (Fig. 6). However, the temperature increases again towards the ground, probably because the air passing Bod $\varnothing$ has been eroded by a heat transfer when flowing out the Skjerstadfjord/Saltenfjord (the air temperature on the ground in Saltdal was below $-10^{\circ} \mathrm{C}$ on the 2 March). Fig. 6 indicates that a reasonable estimate for the boundary layer thickness is $800-1200$ metres. Accordingly, a reasonable estimate for the Rossby radius is between 110 and $140 \mathrm{~km}$.

Since the pressure gradient has an orientation nearly perpendicular to the coast, the Coriolis force will gradually turn the wind to a more longshore direction off the coast. Due to friction the wind will not become completely parallel to the isobars. However, at offshore length scales exceeding the Rossby radius the wind will be inclined less than $20^{\circ}$ to the large-scale pressure pattern. The wind pattern in Fig. 5 is in agreement with this theory.

The wind on 2 March is responsible for most pronounced wind stress in the time period prior to the satellite observations and therefore probably responsible for the most of the observed anomalies in the SST maps. The accumulated daily mean wind stress for the meteorological stations covering the area from the valley inside the fjord to the coastal area outside the fjords are presented in Figs. 7 and 8. These figures demonstrate the 


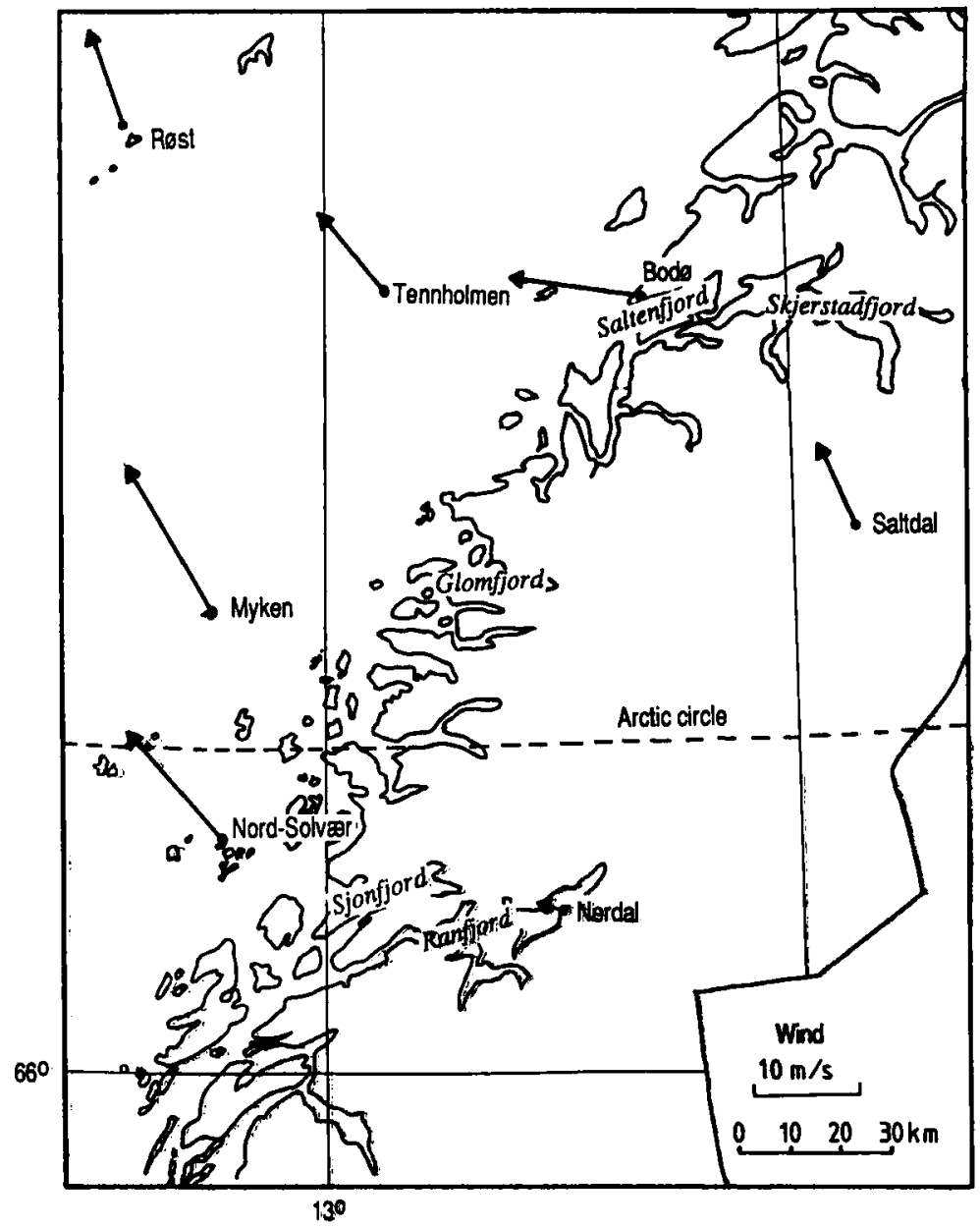

00 UTC

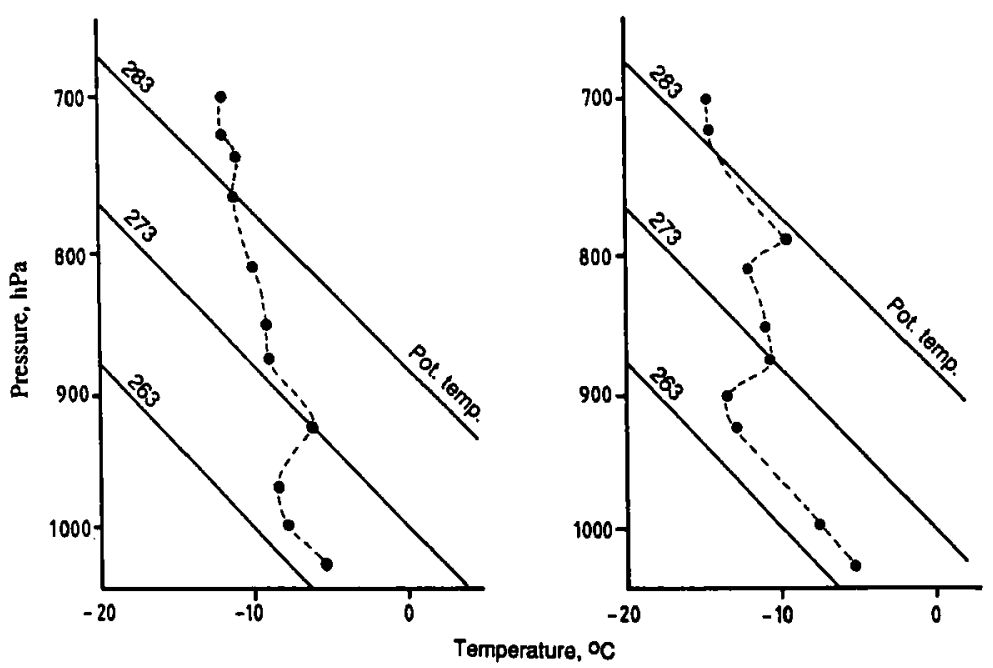

Fig. 5. Daily mean wind in the study area, 2 March 1987 (Fjord names in italics).
Fig. 6. Vertical temperature profiles from Bodø, 2 March 1987 (Radiosonde profile). 
February

March
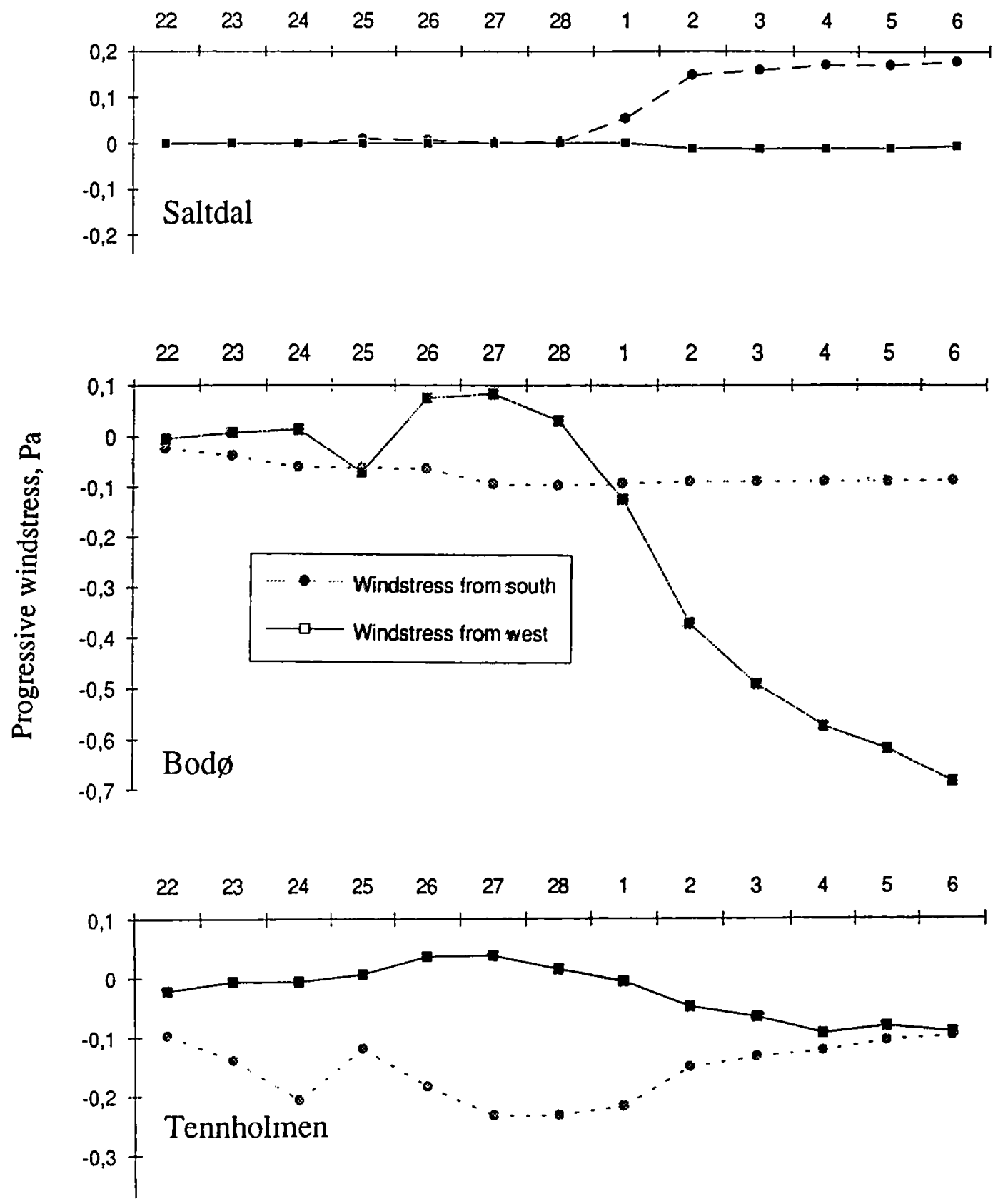

Fig. 7. Wind stress at Saltdal, Bodø, and Tennholmen, 22 February-6 March 1987. 
February

March

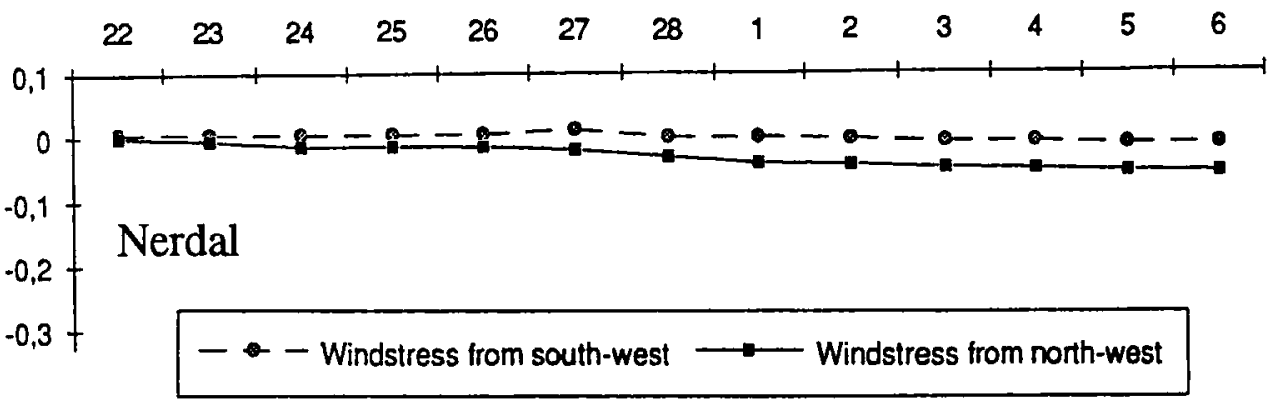

D
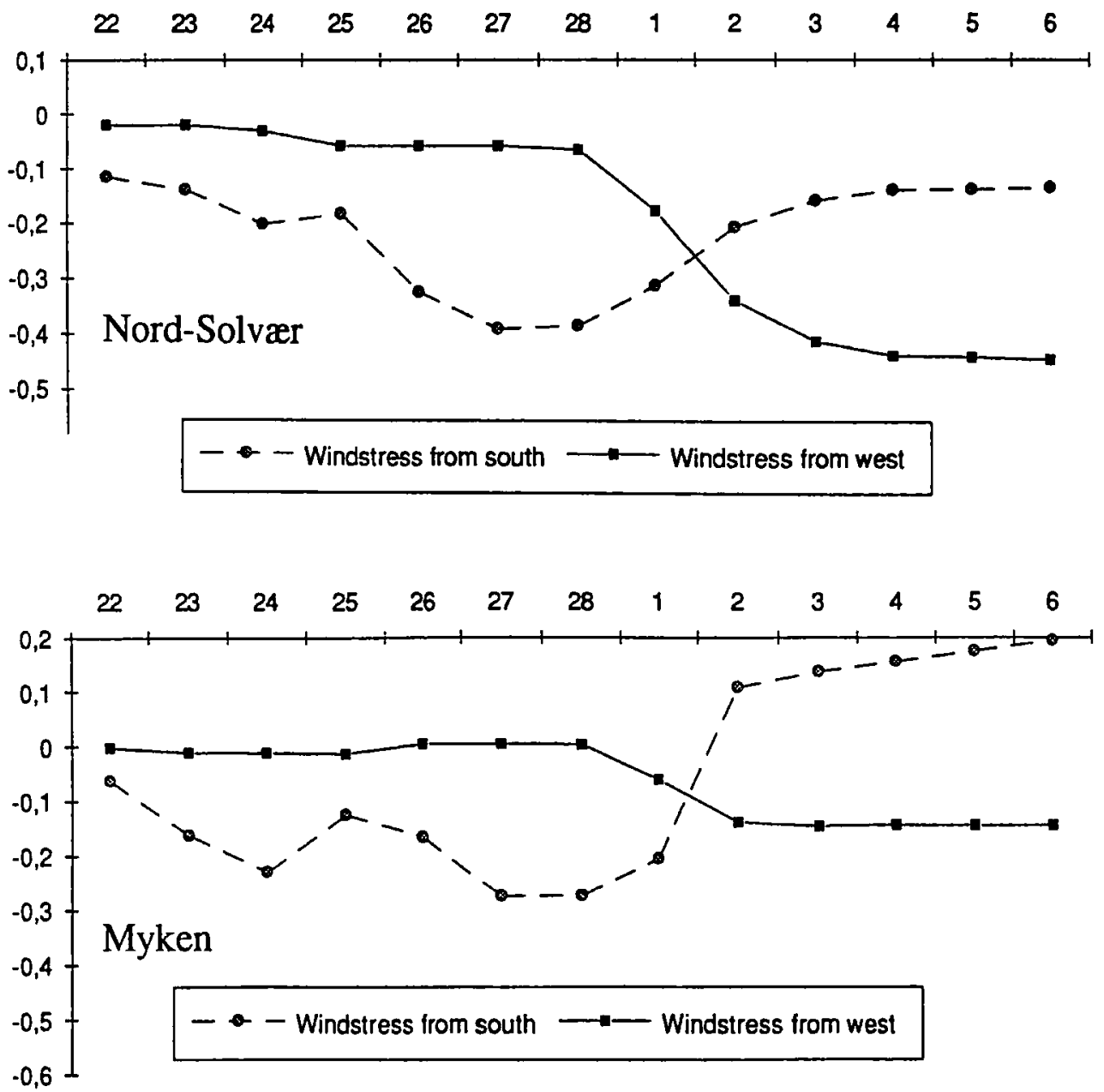

Fig. 8. Wind stress at Nerdal, Nord-Solvær, and Myken, 22 February-6 March 1987. 
local variability of the wind in the fjords and the coastal area. This is most noticeable in the Saltenfjord/Skjerstadfjord area, where the wind decreases both seaward and in the valley beyond the fjord.

\section{Discussion}

As thermal infrared radiation is emitted from the very surface layer, remote sensing data must be treated with great care, especially when there is reason to assume that the surface water is stratified. A thin surface layer is generally stratified shortly after precipitation or solar warming and in areas influenced by fresh water run-off. During periods with great heat loss from the sea surface, the temperature of a thin surface layer may be lower than the average temperature of the surface layer as measured in the usual way (Fedorov \& Sklyarov 1981). It must also be taken into account that local fog can occur where warm and cold air meet. Fog and haze produce artifacts which can show up as area with low sea surface temperatures. The imagery was acquired at 10 am (UTC) on 6 March, when the sun angle in northern Norway was still low. Therefore solar radiation will not have influenced sea surface temperatures. Also, no precipitation which could result in layering of the water was recorded during the days prior to the satellite overpass.

\section{Comparison of the satellite maps and the expected fjord circulation.}

Only a few fjords in the mapped area are sufficiently covered by meteorological observations and available hydrographical data. Four fjords have been chosen for a more thorough discussion in this paper: Ranfjord, Sjonfjord, Glomfjord and Skjerstadfjord (Fig. 5).

Freshwater supply is an important determinant of fjord circulation. Much of the freshwater supply to Norwegian fjords is regulated and utilized for hydro power. Three of the selected fjords have a large freshwater supply in winter, Skjerstadfjord/Saltenfjord, Glomfjord, and Ranfjord. The freshwater supply to Sjonfjord is also regulated, but the freshwater discharge in winter is very low. In late winter the "freshwater fjords" usually have a cold and low saline surface layer, while temperature and salinity increase slightly with depth.
Figs. 7 and 8 show that the wind direction was constantly down-fjord during the week prior to the satellite over-pass. Under such conditions surface water is transported away from the inner part of the fjord and subsurface water is brought up to the surface. This upwelling of warmer intermediate water is clearly visible on the SST maps through a higher temperature. This effect is seen in most of the fjords depicted in Fig. 2. However, in some fjords there is no upwelling at the head of the fjord.

Skjerstadfjord is a special case because of its shallow and narrow entrance, Saltstraumen. This narrow entrance causes a considerable tidal choking, energetically mixing the water as it passes the entrance. This narrow entrance also has a blocking effect on the wind transport out of the fjord. Fig. 2 shows how the cold surface water accumulates in the outer part of Skjerstadfjord, causing an abrupt increase in temperature between Skjerstadfjord and Saltenfjord.

The hydrography in Glomfjord is relatively well known (Molvær et al. 1984). The remotely sensed sea surface temperature in the central part of the fjord, 6 March 1986 , is very similar to the sea surface temperature in the typical depth profile presented in Fig. 3. In Glomfjord there is no upwelling in the inner part of the fjord, probably because the wind effect is much weaker in this fjord than in Skjerstadfjord. There are no wind observations from the Glomfjord area but the indication of light wind is in agreement with the local knowledge about the wind in this area. This area is regarded as considerably less exposed to this kind of wind than Skjerstadfjord and Saltenfjord (Sandmo 1990).

There is a weak upwelling in the inner part of Ranfjord. Ranfjord is a long and channel-shaped fjord. However, the steep sides of the fjord are broken up by side valleys crossing over to the surrounding fjords. In this context the passage from the central part of Ranfjord to Sjonfjord is particularly important. The wind flowing out from Ranfjord is obviously drained over to Sjonfjord through the passage between the central part of Ranfjord and the inner part of Sjonfjord. In the inner part of Ranfjord the temperature decreases down-fjord to the area where the side of the fjord is broken up by the pass to Sjonfjord. A strong upwelling in Sjonfjord indicates that some of the air flows from Ranfjord pass over to Sjonfjord, reinforcing the windfield in that fjord. 


\section{The coastal ocean}

During winter periods with high pressure over Scandinavia the wind on the coast follows the direction of the fjords or blows perpendicular to the coast. As the air moves offshore, the direction will be more parallel to the isobars. This means that the wind turns gradually to a more longshore direction as the distance from the coast increases. Since the Ekman transport is to the right of the wind direction, the shoreward component of the transport will increase offshore. In this way the coastal surface water is transported northward and in towards the coast.

Since cold surface water is transported out of most of the fjords, at the same time as coastal surface water is transported shoreward, there will be a convergence of cold surface water in the coastal zone. This effect is clearly seen in the SST chart presented in Fig. 2.

\section{Concluding remarks}

The satellite image shows the sea surface temperatures at the time of the satellite overpass. As weather conditions usually are relatively stable during cold high-pressure periods, it is assumed that the map is representative for the sea surface temperatures during prolonged cold periods.

During late winter there are sometimes prolonged periods of high air pressure over Scandinavia. The SST charts presented in this paper represent the situation at the end of one such period. Such a weather situation is extremely stable with little variation in the direction of the prevailing winds. Many of the differences that show up in the SST charts, therefore, are probably caused by local topographical inferred variation in the wind field. As a result it will require a comprehensive field observation program to procure enough wind observations to obtain the same information as the SST charts give.

The cold air produced during a period with high pressure over the Scandinavian peninsula will drain out some of the fjords giving down-fjord wind. The winds blowing out of the fjords transport the cold surface water out of the fjords. Off the coast the wind will gradually tend to blow more parallel to the isobars (less than $20^{\circ}$ to the left of the isobars). Since the offshore isobars during such a weather situation will be nearly longshore, the offshore wind will transport sur- face coastal water toward the coast. In this way the coastal zone will be a convergence area for cold water during such a period, if the wind is not too strong.

The weather situation discussed in this paper represents a situation where local coastal zone observations cannot give sufficient information, and satellite observed SST can be an easy way to provide supplementary information.

Acknowledgements. - The satellite images were processed as part of a survcy of sea surface temperatures for aquaculture planning carried out on behalf of the regional development council and the county of Nordland. The authors wish to thank N. T. Hagen and H. K. Marshall for careful reading of and useful comments on this paper.

\section{References}

Børresen, J. A. 1987: Wind Atlas for the North Sea and the Norwegian Sea. The Norwegian Meterological Institute. 183 pp.

Deutscher Wetterdienst 1987: Europaischer Wetterbericht, Vol. 12, Nos. 60-65.

Eilertsen, H. C., Falk-Petersen, S., Hopkins, C. C. E. \& Tande, K. 1981: Ecological Investigations on the plankton community of Balsfjorden, northern Norway. Program for the project, study area, topography, and physical environment. Sarsia 66, 25-34.

Fedorov, K. N. \& Sklyarov, V. E. 1981: Space oceanography: Hopes and realities. Pp. 35-47 in Gower, J. F. R. (ed.): Oceanography from Space.

Haakstad, M. 1984: Basisundersøkelse i Ranfjorden-en marin industriresipient. Hydrografiske undersøkelser 1980-1982. Norsk institutt for vannforskning, Oslo. $48 \mathrm{pp}$.

Johnson, W. B., Jr. 1966: The "geotriptic" wind. Bull. Amer. Meteor. Soc. 47 (9), 982.

Kögeler, J. W. \& Dahle, S. 1991: Remote sensing of sea surface temperatures for aquaculture in nothern Norway. Arctic 44(1), 34-39.

Macklin, S. A., Lackmann, G. M. \& Gray, J. 1988: OffshoreDirected Winds in the Vicinity of Prince William Sound, Alaska. Monthly Weather Review, 116(6), 1289-1301.

Molvzer, J., Knutzen, J., Haakstad, M. \& Tangen, K. 1984: Basisundersoketse $i$ Glomfjorden 1981-1982. Vannutskiftning, vannkvalitet, miljogifter $i$ organismer og organismesamfunn pd grunt vann. Norsk institutt for vannforskning, Oslo. 125 pp.

Nordgaard, O., Normann, U. \& Pettersen, F. 1982: Havmiljødata fra nordnorske fjorder i 1981. Tromura 28. Troms $\emptyset$ Museum, University of Tromsø.

Pritchard, D. W. 1952: Estuarine hydrography. Pp. 243-279 in Landsberg, H. E. (ed.): Advances in Geophysics, Vol. 1. Academic Press.

Sandmo, H. 1990: Nedising på Bodø havn. Varet 14(1), 20-21. Smith, S. 1980: Wind Stress and Heat Flux over the Ocean in Gale Force Winds. J. Phys. Oceanogr. 10(5), 709-726.

Sælen, O. H. 1950: The hydrography of some fjords in northern Norway. Troms Museums Årshefter, Nat. Hist. Avd. Vol. 70, No. 38 (1947). 